\title{
Carotid Atherosclerotic Markers in CADASIL
}

\author{
Jérôme Mawet ${ }^{\mathrm{a}}$ Katayoun Vahedi $^{\mathrm{a}}$ Mounir Aout $^{\mathrm{b}}$ Eric Vicaut ${ }^{\mathrm{b}}$ \\ Marco Duering ${ }^{d, e}$ Pierre Jean Touboul ${ }^{a}$ Martin Dichgans ${ }^{d, e}$ Hugues Chabriat $^{a-c}$ \\ aDepartment of Neurology, Centre de Référence pour les maladies rares des Vaisseaux du Cerveau et de I'Oeil \\ (CERVCO), ${ }^{b}$ Unité de Recherche Clinique, Groupe Hospitalier Lariboisière-Fernand Widal, APHP, Université Paris \\ 7-Denis Diderot, and 'INSERM UMR 740, Faculté de Médecine Villemin, Université Paris 7, Paris, France; \\ ${ }^{\mathrm{d}}$ Institute for Stroke and Dementia Research, and ' Department of Neurology, Klinikum Grosshadern, \\ Ludwig Maximilians University, Munich, Germany
}

\section{Key Words}

Atherosclerosis - Carotid atherosclerosis · CADASIL ·

Carotid duplex ultrasonography $\cdot$ NOTCH3 gene

\begin{abstract}
Purpose: Cerebral autosomal dominant arteriopathy with subcortical infarcts and leukoencephalopathy (CADASIL) is a cerebral small vessel disease caused by mutations of the NOTCH3 gene. Marked variations in disease severity have raised the hypothesis that non-genetic factors may modulate the expressivity of the phenotype. The aim of the current study was to evaluate whether atherosclerosis, assessed by carotid duplex ultrasonography, is associated with variations in the clinical and MRI phenotype of CADASIL. Methods: Data from 144 consecutive patients enrolled in an ongoing prospective cohort study were collected. Degree of disability was assessed by the modified Rankin Scale, that of cognitive impairment by the Mattis Dementia Rating Scale (MDRS). The total volume of the brain, of lacunar lesions and of white matter hyperintensities, the number of cerebral microhemorrhages, and parameters derived from histograms of apparent diffusion coefficient were measured on cerebral MRI. Atherosclerosis was evaluated by B-mode ultrasonography of carotid arteries. Both the carotid intima-media thickness
\end{abstract}

(cIMT) and the presence of carotid plaques or stenosis were recorded. Results: Higher cIMT was found to be independently associated with lower MDRS scores when this score was less than the quartile limit $(p=0.02)$. Only a trend for a positive association was detected between cIMT and the Rankin score $(p=0.06)$. There was no significant association between carotid markers and the occurrence of stroke or MRI parameters except for diffusion data. The mean and peak values of MRI diffusion histograms were found positively associated with the presence of plaques $(p<0.01)$. Conclusion: The results suggest that the severity of atherosclerosis may relate to cognitive decline in CADASIL and that this effect is possibly related to the degree of microstructural cerebral tissue lesions. Longitudinal studies are needed to confirm these results.

Copyright $\odot 2010$ S. Karger AG, Basel

\section{Introduction}

CADASIL (cerebral autosomal dominant arteriopathy with subcortical infarcts and leukoencephalopathy) is a small vessel disease of the brain caused by mutations in the NOTCH3 gene [1]. The clinical hallmarks of CADASIL include attacks of migraine with aura, recurrent lacu-

\section{KARGER}

Fax +41613061234 E-Mail karger@karger.ch www.karger.com

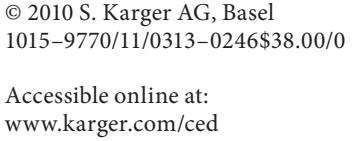


nar stroke, mood disturbances and progressive subcortical dementia [2-4].

To date, with the exception of rare mutations in the EGFR10-11 domain that may affect the clinical expression of the disease, no obvious genotype/phenotype has been demonstrated [5-7]. However, some data suggest that classical vascular risk factors may influence the outcome in CADASIL. In a previous series, Singhal et al. [5] found that active smoking was associated with younger age at first ischemic manifestation. In a cross-sectional study, Viswanathan et al. [8] recently observed that higher levels of $\mathrm{HbA}_{1 \mathrm{C}}$ and systolic blood pressure were related to the number of cerebral microhemorrhages on gradient-echo imaging. Recently, Adib-Samii et al. [9] reported that hypertension and smoking were associated with an increased risk of stroke in 200 CADASIL patients.

In the general population, the carotid intima-media thickness (cIMT) and the presence of carotid plaques evaluated by duplex ultrasonography are considered as early markers of atherosclerosis and have been associated with the severity of systemic atherosclerosis $[10,11]$. They are also independent predictors of both cardiovascular and cerebrovascular events $[12,13]$. Moreover, cIMT has been associated with white-matter hyperintensities on $\mathrm{T}_{2}$-weighted MRI and with cognitive decline in elderly people as were arterial stiffening and endothelial dysfunction [14]. Whether the severity of atherosclerosis can modulate the expression of a specific small vessel disease not related to the current vascular risk factors remains unknown.

In the present study, we hypothesized that atherosclerosis assessed by carotid duplex ultrasonography might have an impact on the clinical or brain MRI phenotype of CADASIL.

\section{Subjects and Methods}

\section{Subjects}

Subjects were drawn from an ongoing prospective cohort study of consecutive patients with CADASIL in Lariboisière Hospital, Paris, between June 2003 and November 2006. Complete study design has been detailed elsewhere $[8,15]$. In summary, in 144 genetically confirmed CADASIL patients, clinical and demographic data were collected. They underwent a general and neurological examination, including an evaluation of the degree of disability based on the modified Rankin Scale (mRS) (poor outcome was defined as $m R S \geq 3$ ). Neuropsychological evaluation with the Mattis Dementia Rating Scale (MDRS) [16] was also performed. The educational level was assessed with a scale from 1 (illiterate) to 7 (university diploma). Note that history of hypertension was defined as previous diagnosis of hypertension ( $>140 / 90)$ or use of antihypertensive treatment for control of blood pressure.
All patients had cerebral MRI and cervical ultrasound examination. All patients had blood drawn for laboratory screening including: complete blood count, glucose, hemoglobin $\mathrm{A}_{1 \mathrm{c}}\left(\mathrm{HbA}_{1 \mathrm{c}}\right)$, cholesterol panel, triglycerides, homocysteine, fibrinogen and CRP.

Informed consent was obtained from each subject or from a relative if the patient was not able to give written consent. The study was approved by an independent ethic committee.

\section{Magnetic Resonance Imaging}

Cerebral MRI scans were obtained by the use of a 1.5-T system (Signa General Electric Medical Systems). 3D $\mathrm{T}_{1}$-weighted sequences, fluid-attenuated inversion recovery (FLAIR), $\mathrm{T}_{2}{ }^{*}$ weighted gradient-echo planar and diffusion-weighted imaging were performed. The methods used for MRI analysis and the validation of the different measurements have been detailed elsewhere $[8,15]$.

White matter hyperintensities (WMH) lesions were analyzed on FLAIR images. The total volume of $\mathrm{WMH}$ was normalized to the intracranial cavity (ICC) in each patient [normalized volume of $\mathrm{WMH}$ or $\mathrm{nWMH}=($ volume of WMH/volume ICC) $\cdot 100]$. To assess the total volume of lacunes, all hypointense lesions with both a signal identical to that of cerebrospinal fluid and a diameter $>2 \mathrm{~mm}$ were selected. The total volume of lacunes in each patient was normalized to the ICC [normalized lacunar volume or $\mathrm{nLV}=$ (volume of lacunes/volume ICC) - 100]. Microhemorrhages were defined as rounded foci $\leq 5 \mathrm{~mm}$ in diameter hypointense on gradient-echo sequences and distinct from vascular flow voids, leptomeningeal hemosiderosis, or non-hemorrhagic subcortical mineralization. The number of microhemorrhages was recorded in each patient. Histograms of apparent diffusion coefficient (ADC) values from $\mathrm{ADC}$ maps were generated for each patient using a bin width equal to $0.1 \times 10^{-4} \mathrm{~mm}^{2} \mathrm{~s}^{-1}$. Voxels containing cerebrospinal fluid were excluded in all patients before calculation using a superior threshold value at $27 \times 10^{-4} \mathrm{~mm}^{2} \mathrm{~s}^{-1}$. To correct for crosssubject differences in brain volume, each histogram was normalized to the total number of brain tissue voxels. Both the mean ADC and diffusion value at the peak (peak value) derived from each histogram were used for analysis. Due to small changes in diffusion values after the upgrade of the MR device and coils that occurred during the study, the analysis of diffusion data was restricted to the 104 patients who had their examination before the upgrade. Determination of global brain volumes from $3 \mathrm{D} \mathrm{T}_{1}$ sequences was performed using the BrainVISA software (CEA, Orsay, France; http:// brainvisa.info) as previously detailed [17]. Brain parenchymal fraction (BPF) was defined as the ratio of brain tissue volume to total intracranial cavity volume (BPF = brain tissue volume/ICC).

\section{Ultrasonography}

Participants had a cervical ultrasound B-mode examination (Acuson, 7-MHz probe) performed at inclusion. All examinations were performed by trained physicians. Longitudinal and crosssectional ultrasound images were taken bilaterally throughout the extracranial portion of the common carotid artery (CCA) and of the bifurcation and origin of the internal carotid artery bilaterally. Plaque was defined as a focal structure encroaching into the lumen of at least $0.5 \mathrm{~mm}$ or a thickening $\geq 1.5 \mathrm{~mm}$ (distance between media-adventitia interface to the intima-lumen interface) and stenosis was defined as a plaque of more than $20 \%$ of the lumen axe in cross section [18]. Carotid atherosclerosis lesions were 
Table 1. Logistic regression according to the presence of carotid plaques or stenosis and linear regression with cIMT

\begin{tabular}{|c|c|c|c|c|c|c|c|}
\hline \multirow[t]{3}{*}{ Variable } & \multicolumn{4}{|c|}{ Plaques ( $n=48 / 144$ patients) } & \multicolumn{3}{|c|}{ cIMT ( $\mathrm{n}=134$ patients) } \\
\hline & \multicolumn{2}{|l|}{ univariate analysis } & \multicolumn{2}{|c|}{ multivariate analysis } & \multicolumn{2}{|c|}{ univariate analysis } & \multirow{2}{*}{$\begin{array}{l}\text { multivariate analysis } \\
\mathrm{p} \text { value }\end{array}$} \\
\hline & OR $[95 \% \mathrm{CI}]$ & $\mathrm{p}$ value & OR $[95 \% \mathrm{CI}]$ & $\mathrm{p}$ value & $\begin{array}{l}\text { Pearson } \\
\text { correlation } \\
\text { coefficient }\end{array}$ & $\mathrm{p}$ value & \\
\hline Age (10-year increase) & $2.34[1.60 ; 3.44]$ & $<0.0001$ & $2.49[1.64 ; 3.79]$ & $<0.0001$ & 0.644 & $<0.0001$ & $<0.0001$ \\
\hline Sex (male vs. female) & $2.80[1.36 ; 5.78]$ & 0.0053 & $3.11[1.39 ; 6.97]$ & 0.0059 & 0.149 & 0.0852 & \\
\hline Educational level & $1.17[0.94 ; 1.47]$ & 0.1559 & & & -0.294 & 0.0007 & 0.0034 \\
\hline $\begin{array}{l}\text { History of high blood pressure } \\
\quad \text { (yes vs. no) }\end{array}$ & $1.52[0.62 ; 3.74]$ & 0.3590 & & & 0.039 & 0.6529 & \\
\hline $\begin{array}{l}\text { History of hypercholesterolemia } \\
\text { (yes vs. no) }\end{array}$ & & & & & & & \\
\hline History of diabetes (yes vs. no) & $\begin{array}{l}1.70[0.84 ; 3.42] \\
0.99[0.09 ; 11.19]\end{array}$ & $\begin{array}{l}0.1385 \\
0.9931\end{array}$ & & & $\begin{array}{r}0.086 \\
-0.107\end{array}$ & $\begin{array}{l}0.3225 \\
0.2201\end{array}$ & \\
\hline Current or ex-smoker (yes vs. no) & $1.26[0.63 ; 2.53]$ & 0.5149 & & & 0.021 & 0.8091 & \\
\hline SBP, mm Hg & $1.02[1.00 ; 1.04]$ & 0.0297 & & & 0.102 & 0.2527 & \\
\hline DBP, mm Hg & $1.01[0.98 ; 1.04]$ & 0.5364 & & & 0.039 & 0.6613 & \\
\hline BMI & $0.98[0.90 ; 1.07]$ & 0.6598 & & & 0.052 & 0.5901 & \\
\hline $\mathrm{HDL}, \mathrm{mmol} / \mathrm{l}$ & $0.72[0.30 ; 1.74]$ & 0.4662 & & & -0.026 & 0.7777 & \\
\hline LDL, mmol/l & $1.22[0.85 ; 1.76]$ & 0.2775 & & & 0.106 & 0.2223 & \\
\hline Total cholesterol, mmol/l & $1.18[0.89 ; 1.57]$ & 0.2434 & & & 0.103 & 0.2367 & \\
\hline Triglycerides, mmol/l & $2.00[1.10 ; 3.63]$ & 0.0223 & & & 0.140 & 0.1070 & \\
\hline Glycated hemoglobin & $1.29[0.63 ; 2.65]$ & 0.4882 & & & 0.084 & 0.3355 & \\
\hline Blood glucose, mmol/l & $0.98[0.70 ; 1.38]$ & 0.9047 & & & -0.027 & 0.7577 & \\
\hline Homocysteine, $\mu \mathrm{mol} / \mathrm{l}$ & $1.03[0.95 ; 1.11]$ & 0.5136 & & & 0.168 & 0.0551 & \\
\hline CRP, mg/l & $1.00[0.95 ; 1.05]$ & 0.9374 & & & 0.099 & 0.2542 & \\
\hline Fibrinogen, g/l & $1.48[0.91 ; 2.40]$ & 0.1125 & & & 0.315 & 0.0003 & \\
\hline
\end{tabular}

classified as either no plaque or presence of plaque or stenosis. As recommended, the near and far walls of the middle parts of the right and left CCA were scanned longitudinally to assess the best angle of incidence for cIMT measurements. Then an average cIMT measurement was performed on a $10-\mathrm{mm}$ segment at the far wall of each CCA using dedicated software $\left(\mathrm{M}^{\prime} \mathrm{Ath}{ }^{\circledR}-\mathrm{Std}^{\odot}\right)$. The average of right and left CCA IMT measurements was used for analysis. The inter- and intrarater reliability was not calculated in the present study but was previously assessed in large studies and was found to be good [19].

\section{Statistical Methods}

Analyses were conducted using SAS ${ }^{\circledR}$ software v.9.1 (SAS Institute Inc., Cary, N.C., USA). Data are summarized as frequencies and percentages for categorical data and as mean and standard deviation for continuous variables. Odds ratios (OR) are reported with $95 \%$ confidence intervals (95\% CIs).

First analysis was performed to identify factors associated with carotid plaques or stenosis and with cIMT among the following variables: age, sex, educational level, history of hypertension, history of hypercholesterolemia, history of diabetes, smoking status, systolic blood pressure, diastolic blood pressure, body mass index, HDL, LDL, total cholesterol, triglycerides, $\mathrm{HbA}_{1 \mathrm{C}}$, blood glucose, homocysteine, CRP, and fibrinogen level.

The second analysis used the same procedure to identify correlations between clinical and radiological markers of CADASIL by adding either carotid plaque or stenosis and cIMT among the evaluated factors.
For binary endpoints (presence of carotid plaques or stenosis, presence of stroke, disability, cognitive impairment and microhemorrhages), univariate logistic regressions were first performed. Variables statistically significant at a 15\% threshold in the univariate analysis were then introduced into a multivariable stepwise logistic regression to identify independent correlates of these endpoints. Validity of all models was evaluated by the bootstrapping procedure ( $\mathrm{n}=1,000$ bootstrap samples).

For the continuous measures (cIMT, extent of white matter lesions, total volume of lacunes, BPF and mean ADC), Pearson correlation coefficients were obtained, and multivariable stepwise linear regressions were used to find the linear models that best predict continuous measures. Resampling procedures were used for validation of these models. The significance level was fixed at $5 \%$.

\section{Results}

\section{Main Cohort Characteristics}

The mean age in the cohort was $52.6 \pm 11.9$ years (median 52.8, range 24.1-77.5) and 72 men (50\%) were included. Ninety-three subjects $(64.6 \%)$ had at least one ischemic stroke before inclusion and $32(22.2 \%)$ had a $\mathrm{mRS} \geq 3$. The median MDRS score was 140 and its lower quartile limit was 127 . The frequency of vascular risk factors was as follows: history of hypertension $(n=24 / 144$ subjects, $16.7 \%)$, 
Table 2. Logistic regression using MDRS score at 140 or at 127 as cutoff values for the presence of cognitive impairment

\begin{tabular}{|c|c|c|c|c|c|c|c|c|}
\hline \multirow[t]{3}{*}{ Variable } & \multicolumn{4}{|c|}{ MDRS $\leq 140(n=68 / 130$ patients $)$} & \multicolumn{4}{|c|}{ MDRS $\leq 127$ ( $\mathrm{n}=35 / 130$ patients $)$} \\
\hline & \multicolumn{2}{|l|}{ univariate analysis } & \multicolumn{2}{|c|}{ multivariate analysis } & \multicolumn{2}{|l|}{ univariate analysis } & \multicolumn{2}{|c|}{ multivariate analysis } \\
\hline & OR $[95 \% \mathrm{CI}]$ & $\mathrm{p}$ value & OR $[95 \% \mathrm{CI}]$ & $\mathrm{p}$ value & OR $[95 \% \mathrm{CI}]$ & $\mathrm{p}$ value & OR $[95 \% \mathrm{CI}]$ & $\mathrm{p}$ value \\
\hline cIMT (0.05-mm increase) & $1.50[1.20 ; 1.88]$ & 0.0004 & & & $1.77[1.39 ; 2.26]$ & $<0.0001$ & $1.40[1.05 ; 1.88]$ & 0.0234 \\
\hline Plaques (yes vs. no) & $1.16[0.55 ; 2.42]$ & 0.6988 & & & $2.64[1.18 ; 5.91]$ & 0.0179 & & \\
\hline Age (10-year increase) & $2.17[1.52 ; 3.10]$ & $<0.0001$ & $2.10[1.46 ; 3.06]$ & 0.0001 & $3.20[1.97 ; 5.21]$ & $<0.0001$ & $2.19[1.24 ; 3.87]$ & 0.0069 \\
\hline Sex (male vs. female) & $1.98[0.98 ; 3.98]$ & 0.0556 & & & $1.96[0.89 ; 4.35]$ & 0.0969 & & \\
\hline Educational level & $0.63[0.49 ; 0.81]$ & 0.0003 & $0.64[0.49 ; 0.84]$ & 0.0011 & $0.75[0.56 ; 1]$ & 0.0472 & & \\
\hline \multicolumn{9}{|l|}{ History of high blood pressure } \\
\hline (yes vs. no) & $2.69[0.97 ; 7.46]$ & 0.0568 & & & $0.85[0.29 ; 2.53]$ & 0.7723 & & \\
\hline \multicolumn{9}{|l|}{ History of hypercholesterolemia } \\
\hline (yes vs. no) & $2.56[1.25 ; 5.23]$ & 0.01 & & & $2.42[1.08 ; 5.42]$ & 0.0310 & & \\
\hline History of diabetes (yes vs. no) & $1.88[0.17 ; 21.23]$ & 0.611 & & & $1.41[0.12 ; 16.06]$ & 0.7823 & & \\
\hline Current or ex-smoker (yes vs. no) & $0.91[0.46 ; 1.82]$ & 0.7889 & & & $0.71[0.32 ; 1.56]$ & 0.3951 & & \\
\hline SBP, mm Hg & $1.01[0.99 ; 1.03]$ & 0.4442 & & & $1.01[0.99 ; 1.04]$ & 0.3783 & & \\
\hline DBP, mm Hg & $1[0.97 ; 1.03]$ & 0.8926 & & & $1[0.96 ; 1.04]$ & 0.9789 & & \\
\hline BMI & $1.06[0.97 ; 1.17]$ & 0.1974 & & & $1[0.9 ; 1.12]$ & 0.9474 & & \\
\hline $\mathrm{HDL}, \mathrm{mmol} / \mathrm{l}$ & $0.61[0.26 ; 1.46]$ & 0.2686 & & & $0.4[0.14 ; 1.13]$ & 0.0841 & & \\
\hline LDL, mmol/l & $0.92[0.64 ; 1.3]$ & 0.6225 & & & $0.75[0.51 ; 1.12]$ & 0.1581 & & \\
\hline Total cholesterol, mmol/l & $0.95[0.72 ; 1.24]$ & 0.7057 & & & $0.79[0.58 ; 1.07]$ & 0.1261 & & \\
\hline Triglycerides, mmol/l & $1.54[0.85 ; 2.79]$ & 0.1538 & & & $1.35[0.75 ; 2.43]$ & 0.3144 & & \\
\hline Glycated hemoglobin & $1.32[0.62 ; 2.8]$ & 0.4765 & & & $0.69[0.28 ; 1.69]$ & 0.4156 & & \\
\hline Blood glucose, mmol/l & $0.95[0.68 ; 1.33]$ & 0.7687 & & & $0.72[0.5 ; 1.03]$ & 0.0740 & & \\
\hline Homocysteine, $\mu \mathrm{mol} / \mathrm{l}$ & $1.09[1 ; 1.2]$ & 0.0444 & & & $1.08[0.99 ; 1.18]$ & 0.0958 & & \\
\hline $\mathrm{CRP}, \mathrm{mg} / \mathrm{l}$ & $1.01[0.97 ; 1.06]$ & 0.6327 & & & $1.04[0.99 ; 1.09]$ & 0.1335 & & \\
\hline Fibrinogen, g/l & $1.4[0.85 ; 2.29]$ & 0.1876 & & & $1.97[1.12 ; 3.48]$ & 0.0186 & & \\
\hline
\end{tabular}

hypercholesterolemia $(\mathrm{n}=65,45.5 \%)$, diabetes $(\mathrm{n}=3$, $2.1 \%)$, current or ex-smoking ( $\mathrm{n}=69,48.3 \%)$.

\section{Vascular Risk Factors and Carotid Atherosclerosis (table 1)}

Carotid plaques or stenosis were found in 48 out of 144 patients (33.3\%). In univariate analysis, carotid plaques or stenosis were found associated with age, male sex and systolic blood pressure (table 1), in multivariate analysis the association was found significant only with age and male sex.

134 out of 144 patients had cIMT measurement available. The mean cIMT was $0.63 \pm 0.1 \mathrm{~mm}$ (median 0.61, range 0.47-0.91). cIMT was found associated with age, educational level, and fibrinogen in univariate analysis, only with age and educational level in multivariate analysis (see table 1).

\section{Main Clinical Manifestations and Carotid}

Atherosclerosis (table 2)

Cognition

Using the median MDRS score of 140 as the cutoff value for the presence of moderate cognitive impairment, we found, in univariate analysis, that age, educational level, cIMT, the presence of plaques, a positive history of hypercholesterolemia and homocysteine level were significantly associated with MDRS $<140$. In multivariate analysis, only higher age and lower educational level were independently correlated with moderate cognitive impairment (AUC 0.777 [0.968; 0.857], optimism 0.77\%).

When using the lower quartile limit of MDRS (127) as the cutoff value for the presence of severe cognitive impairment, while univariate analysis showed a significant association with cIMT, the presence of plaques, age, male sex, educational level, hypercholesterolemia and fibrinogen level, multivariate analysis showed that only higher cIMT and older age were the only factors independently associated with lower cognitive performances (AUC 0.833 [0.761; 0.905], optimism 0.75\%).

\section{Disability and Stroke}

Thirty-two out of 144 (22.2\%) patients were disabled ( $m R S \geq 3$ ). In table 3 , the factors associated with $\mathrm{mRS} \geq 3$ and stroke in multivariate analysis are presented. When the inclusion of the variable 'age' was forced in the model, we found higher age and lower level of $\mathrm{HbA}_{1 \mathrm{C}}$ independently associated with disability and a trend for an association between higher cIMT and disability. 
Table 3. Summary of factors associated with different clinical or MRI markers after multivariate analysis

\begin{tabular}{|c|c|c|c|c|}
\hline $\begin{array}{l}\text { Clinical and MRI variable } \\
\text { tested in the model }\end{array}$ & $\begin{array}{l}\text { Markers with } \\
\text { significant association }\end{array}$ & $\begin{array}{l}\text { Regression } \\
\text { parameter }^{1}[95 \% \mathrm{CI}]\end{array}$ & $\mathrm{p}$ & $\begin{array}{l}\text { AUC }[95 \% \mathrm{CI}] \\
\text { or } \mathrm{R}^{2} \text {, optimism }\end{array}$ \\
\hline $\mathrm{mRS} \geq 3(\mathrm{n}=32 / 144)$ & $\begin{array}{l}\text { cIMT }(0.05-\mathrm{mm} \text { increase }) \\
\text { age ( } 10 \text {-year increase) } \\
\text { glycated hemoglobin }\end{array}$ & $\begin{array}{l}1.31[0.99 ; 1.72] \\
2.10[1.22 ; 3.61] \\
0.12[0.03 ; 0.49]\end{array}$ & $\begin{array}{l}0.0598 \\
0.0073 \\
0.003\end{array}$ & $\begin{array}{l}0.809[0.725 ; 0.894] \\
2 \%\end{array}$ \\
\hline $\begin{array}{l}\text { Clinical history of stroke } \\
\qquad(n=93 / 144)\end{array}$ & $\begin{array}{l}\text { age ( } 10 \text {-year increase) } \\
\text { sex (male vs. female) }\end{array}$ & $\begin{array}{l}1.56[1.14 ; 2.14] \\
2.38[1.15 ; 4.93]\end{array}$ & $\begin{array}{l}0.0055 \\
0.0191\end{array}$ & $\begin{array}{l}0.662[0.562 ; 0.763] \\
1.3 \%\end{array}$ \\
\hline WMH & age & $0.19[0.13 ; 0.25]$ & $<0.0001$ & $\begin{array}{r}21.2 \% \\
1.7 \%\end{array}$ \\
\hline Total volume of lacunes & $\begin{array}{l}\text { age } \\
\text { LDL }\end{array}$ & $\begin{array}{c}0.04[0.02 ; 0.05] \\
-0.06[-0.11 ;-0.00]\end{array}$ & $\begin{array}{l}0.0002 \\
0.0389\end{array}$ & $\begin{array}{r}11.9 \% \\
2.6 \%\end{array}$ \\
\hline Mean ADC & $\begin{array}{l}\text { presence of carotid plaques } \\
\text { or stenosis } \\
\text { age } \\
\text { LDL }\end{array}$ & $\begin{array}{l}1.09[0.42 ; 1.76] \\
0.04[0.01 ; 0.07] \\
-0.57[-0.94 ;-0.20]\end{array}$ & $\begin{array}{l}0.0018 \\
0.0121 \\
0.0029\end{array}$ & $\begin{array}{r}27.4 \% \\
5.5 \%\end{array}$ \\
\hline $\mathrm{BPF}$ & $\begin{array}{l}\text { age } \\
\text { sex }\end{array}$ & $\begin{array}{l}-0.25[-0.36 ;-0.14] \\
-3.70[-6.18 ;-1.22]\end{array}$ & $\begin{array}{r}<0.0001 \\
0.0039\end{array}$ & $\begin{array}{r}29.2 \% \\
3.4 \%\end{array}$ \\
\hline Presence of microhemorrhages & $\begin{array}{l}\text { age ( } 10 \text {-year increase) } \\
\text { systolic blood pressure }\end{array}$ & $\begin{array}{l}1.84[1.08 ; 3.15] \\
1.03[1.00 ; 1.06]\end{array}$ & $\begin{array}{l}0.0248 \\
0.0292\end{array}$ & $\begin{array}{l}0.758[0.654 ; 0.862] \\
1.5 \%\end{array}$ \\
\hline
\end{tabular}

\footnotetext{
${ }^{1}$ Regression parameter stands for OR and 95\% CI or slope and 95\% CI in logistic regression or linear regression, respectively. Only significant results obtained in multivariate analysis are shown.
}

Ninety-three out of 144 patients had a history of symptomatic stroke. The multivariate analysis revealed only higher age and male sex to be independently associated with stroke in the cohort but not the markers of atherosclerosis (cIMT and plaques).

\section{Brain MRI Markers and Atherosclerosis}

The significant associations observed in multivariate analysis are presented in table 3; the extent of white matter lesions in the 144 CADASIL patients was only associated with age but not with the other parameters (table 3).

For the total volume of lacunes, we found a significant association with increasing age and with lower HDL level. The mean ADC was independently associated with the presence of plaques or stenosis, higher age and higher LDL. The same significant association was obtained between peak value of diffusion histograms and both higher LDL and the presence of plaques. The presence of two or more microhemorrhages was associated with increasing age and with higher systolic blood pressure. BPF was inversely correlated with age and was significantly lower in men compared to women.

\section{Discussion}

In this large prospective cohort of CADASIL patients, we found that atherosclerosis has an impact, although small, on the clinical phenotype of this genetic non-atherosclerotic vascular disease of the brain. Indeed, in patients with the lowest cognitive performances, CIMT and age were found to be independently and inversely correlated with the MDRS. Interestingly, this association was not detected in patients with moderate cognitive impairment in whom age and education level were the only predictors of cognitive performances. These results first confirm the major role of aging in the course of CADASIL and second suggest that educational level may have a positive impact on cognitive function in CADASIL during its early stages, while atherosclerosis may play a negative role at more advanced stage of the disease when cognitive decline has already occurred. However, the identified link between atherosclerosis and cognitive decline in this cohort of CADASIL patients does not mean necessarily a causal relationship. First, cognitive impairment may magnify vascular risk factors through a reduction of self-care. Second, atherosclerosis and dementia may share 
common unknown risk factors including potential genetic factors. Interestingly, cIMT has also been associated with more severe cognitive alterations in cohort studies of Alzheimer's disease [20-22]. Our data suggest that atherosclerosis may also have an impact on the course of non-atherosclerotic small vessel disease of the brain.

In the present study, we were unable to demonstrate any strong association between atherosclerosis and disability assessed by mRS, which is a score more correlated to motor than cognitive impairment. We also failed to show any significant association between atherosclerosis and the occurrence of stroke in CADASIL. It is, however, known that the frequency of stroke is not a major determinant of clinical severity in CADASIL, which at its advanced stages has a more progressive course [15].

Since cognitive impairment is strongly related to brain MRI lesions in CADASIL, we searched for an association between the most important MRI markers of the disease and carotid markers of atherosclerosis. The presence of carotid plaques or stenosis was found to be significantly associated with both the mean and peak values of cerebral diffusion histograms. These findings suggest that atherosclerosis may interact with the severity of microstructural cerebral tissue lesions in CADASIL. In contrast, in multivariate analysis, no significant association was detected between cIMT or carotid plaques or stenosis and the total load of lacunar infarctions, extent of WMH, number of microhemorrhages, or BPF. As expected, age was found to be strongly associated with all studied brain MRI parameters of the disease [2].

This study has several limitations. First, we did not use quantitative data such as the surface or volume of carotid plaques, which may be more specific for the evaluation of the severity of atherosclerosis than the degree of carotid stenosis [23]. Second, we did not consider in the multivariate analysis the impact of the underlying Notch $3 \mathrm{mu}-$ tations nor studied other genotypes like ApoE. However, although ApoE genotype is strongly related to cognitive impairment in the general population, it has not been found to be associated with the clinical severity of CADASIL [5]. In addition, there is no data to support a genotype phenotype correlation in CADASIL [9], except rare mutations within the ligand-binding domain of Notch3 that may influence the phenotype of the disease [7]. Furthermore, when the analyses were performed after exclusion of the 8 patients harboring this mutation in EGFR1011 in the cohort, the overall results remained unchanged (data not shown). Finally, there are also different biases related to this cohort of a rare disorder that may also preclude to observe stronger effects of atherosclerosis and a significant association between cIMT and the usual vascular risk factors such as the relatively young age of participants, their selection based on the presence of MRI lesions not explained by vascular risk factors, their high education level, active prevention of vascular risk factors and strong medical follow-up.

In conclusion, the results of this study suggest that atherosclerosis may influence, although subtly, the cognitive decline in CADASIL, which may occur through an increase in microstructural cerebral tissue loss. Longitudinal studies in larger population of patients are needed to confirm the impact of atherosclerosis on the phenotype of the disease and to determine whether treating classical vascular risk factors of atherosclerosis may improve the course of the disease.

\section{Acknowledgements}

This work was supported by PHRC grant AOR 02-001 and AOM 08-076 (DRC/APHP) and performed with the help of ARNEVA (Association de Recherche en Neurologie Vasculaire), Hopital Lariboisière, France, and under the corporate patronage of Bouygues Co. J.M. was supported by a grant from the Servier Institute. The authors are grateful to V. Adraï, R. Cumurciuc, M. Sarov and R. Sciascia for their help in ultrasonic acquisitions.

\section{References}

Carotid Atherosclerotic Markers in CADASIL
1 Joutel A, Corpechot C, Ducros A, Vahedi K, Chabriat H, Mouton P, Alamowitch S, Domenga V, Cecillion M, Marechal E, Maciazek J, Vayssiere C, Cruaud C, Cabanis EA, Ruchoux MM, Weissenbach J, Bach JF, Bousser MG, Tournier-Lasserve E: Notch3 mutations in CADASIL, a hereditary adultonset condition causing stroke and dementia. Nature 1996;383:707-710.

2 Chabriat H, Vahedi K, Iba-Zizen MT, Joutel A, Nibbio A, Nagy TG, Krebs MO, Julien J, Dubois B, Ducrocq X, et al: Clinical spec- trum of CADASIL: a study of 7 families. Cerebral autosomal dominant arteriopathy with subcortical infarcts and leukoencephalopathy. Lancet 1995;346:934-939.

3 Dichgans M, Mayer M, Uttner I, Bruning R, Muller-Hocker J, Rungger G, Ebke M, Klockgether T, Gasser T: The phenotypic spectrum of CADASIL: clinical findings in 102 cases. Ann Neurol 1998;44:731-739.

4 Chabriat H, Joutel A, Dichgans M, TournierLasserve E, Bousser MG: CADASIL. Lancet Neurol 2009;8:643-653. 
5 Singhal S, Bevan S, Barrick T, Rich P, Markus HS: The influence of genetic and cardiovascular risk factors on the CADASIL phenotype. Brain 2004;127:2031-2038.

6 Opherk C, Peters N, Holtmannspotter M, Gschwendtner A, Muller-Myhsok B, Dichgans M: Heritability of MRI lesion volume in CADASIL: evidence for genetic modifiers. Stroke 2006;37:2684-2689.

7 Monet-Lepretre M, Bardot B, Lemaire B, Domenga V, Godin O, Dichgans M, Tournier-Lasserve E, Cohen-Tannoudji M, Chabriat $\mathrm{H}$, Joutel A: Distinct phenotypic and functional features of CADASIL mutations in the Notch3 ligand binding domain. Brain 2009; 132:1601-1612.

8 Viswanathan A, Guichard JP, Gschwendtner A, Buffon F, Cumurcuic R, Boutron C, Vicaut E, Holtmannspotter M, Pachai C, Bousser MG, Dichgans M, Chabriat H: Blood pressure and haemoglobin $A_{1 c}$ are associated with microhaemorrhage in CADASIL: a two-centre cohort study. Brain 2006;129: 2375-2383.

9 Adib-Samii P, Brice G, Martin RJ, Markus HS: Clinical spectrum of CADASIL and the effect of cardiovascular risk factors on phenotype: study in 200 consecutively recruited individuals. Stroke 2010;41:630-634.

10 Bots ML, Hofman A, Grobbee DE: Common carotid intima-media thickness and lower extremity arterial atherosclerosis. The Rotterdam Study. Arterioscler Thromb 1994;14: 1885-1891.

11 Allan PL, Mowbray PI, Lee AJ, Fowkes FG: Relationship between carotid intima-media thickness and symptomatic and asymptomatic peripheral arterial disease. The Edinburgh Artery Study. Stroke 1997;28:348-353.
12 Lorenz MW, Markus HS, Bots ML, Rosvall M, Sitzer M: Prediction of clinical cardiovascular events with carotid intima-media thickness. A systematic review and metaanalysis. Circulation 2007;115:459-467.

13 Tsivgoulis G, Vemmos K, Papamichael C, Spengos K, Manios E, Stamatelopoulos K, Vassilopoulos D, Zakopoulos N: Common carotid artery intima-media thickness and the risk of stroke recurrence. Stroke 2006;37: 1913-1916

14 Kearney-Schwartz A, Rossignol P, Bracard S, Felblinger J, Fay R, Boivin JM, Lecompte T, Lacolley P, Benetos A, Zannad F: Vascular structure and function is correlated to cognitive performance and white matter hyperintensities in older hypertensive patients with subjective memory complaints. Stroke 2009; 40:1229-1236.

15 Viswanathan A, Godin O, Jouvent E, O'Sullivan M, Gschwendtner A, Peters N, Duering M, Guichard JP, Holtmannspotter M, Dufouil C, Pachai C, Bousser MG, Dichgans $\mathrm{M}$, Chabriat $\mathrm{H}$ : Impact of MRI markers in subcortical vascular dementia: a multimodal analysis in CADASIL. Neurobiol Aging 2010;31:1629-1636.

16 Mattis S: Dementia Rating Scale. Odessa, Psychological Assessment Resources, 1988.

17 Jouvent E, Viswanathan A, Mangin JF, O'Sullivan M, Guichard JP, Gschwendtner A, Cumurciuc R, Buffon F, Peters N, Pacha C, Bousser MG, Dichgans M, Chabriat H: Brain atrophy is related to lacunar lesions and tissue microstructural changes in CADASIL. Stroke 2007;38:1786-1790.
18 Touboul PJ, Hennerici MG, Meairs S, Adams $\mathrm{H}$, Amarenco P, Bornstein N, Csiba L, Desvarieux $M$, Ebrahim S, Fatar M, Hernandez Hernandez R, Jaff M, Kownator S, Prati P, Rundek T, Sitzer M, Schminke U, Tardif JC, Taylor A, Vicaut E, Woo KS, Zannad F, Zureik M: Mannheim Carotid Intima-Media Thickness Consensus (2004-2006). An update on behalf of the Advisory Board of the 3rd and 4th Watching the Risk Symposium, 13th and 15th European Stroke Conferences, Mannheim, Germany, 2004, and Brussels, Belgium, 2006. Cerebrovasc Dis 2007;23:7580.

19 O'Leary DH, Polak JF, Kronmal RA, Manolio TA, Burke GL, Wolfson SK Jr: Carotidartery intima and media thickness as a risk factor for myocardial infarction and stroke in older adults. Cardiovascular Health Study Collaborative Research Group. N Engl J Med 1999;340:14-22.

20 Muller M, Grobbee DE, Aleman A, Bots M, van der Schouw YT: Cardiovascular disease and cognitive performance in middle-aged and elderly men. Atherosclerosis 2007;190: 143-149.

21 Silvestrini M, Gobbi B, Pasqualetti P, Bartolini M, Baruffaldi R, Lanciotti C, Cerqua R, Altamura C, Provinciali L, Vernieri F: Carotid atherosclerosis and cognitive decline in patients with Alzheimer's disease. Neurobiol Aging 2009;30:1177-1183.

22 Iadecola C, Gorelick PB: Converging pathogenic mechanisms in vascular and neurodegenerative dementia. Stroke 2003;34:335337.

23 Spence JD: Technology insight: ultrasound measurement of carotid plaque - patient management, genetic research, and therapy evaluation. Nat Clin Pract Neurol 2006;2: 611-619. 